\title{
Emergency Neonatal Obstetric Cares at Cocody University Hospital: Overview of Instrumental Extraction
}

\author{
Kakou Charles*, Kasse Raoul, Kouame Arthur, Koime Hervé, Effoh Denis, Gondo Diomandé, \\ Boni Serge
}

Cocody University Hospital, Abidjan, Côte d'Ivoire

Email: *kakoucharles@yahoo.fr

How to cite this paper: Charles, K., Raoul, K., Arthur, K., Hervé, K., Denis, E., Diomandé, G. and Serge, B. (2017) Emergency Neonatal Obstetric Cares at Cocody University Hospital: Overview of Instrumental Extraction. Open Journal of Obstetrics and Gynecology, 7, 1086-1091.

https://doi.org/10.4236/ojog.2017.711109

Received: August 23, 2017

Accepted: October 15, 2017

Published: October 18, 2017

Copyright $\odot 2017$ by authors and Scientific Research Publishing Inc. This work is licensed under the Creative Commons Attribution International License (CC BY 4.0).

http://creativecommons.org/licenses/by/4.0/

\begin{abstract}
Objectives: The aim of this study was to show an overview of situation of instrumental extraction at the maternity of Cocody University Hospital by determining availability and assessing the maternal and fetal prognosis. Patients and method: it was a retrospective study with a descriptive purpose on 6 months from January 1 to June 31, 2015. It concerned all patients admitted in the expulsive phase of labor delivery room and with an indication of fetal instrumental extraction and the state of their newborns at birth. Results: We saved 2288 vaginal deliveries; including 28 instrumental deliveries on 104 indications of instrumental extraction is an implementation rate of $26.9 \%$ (16 by vacuum extractor and 12 forceps). Among patients with indication but without instrumental extraction $(n=76)$, there is $42.3 \%$ vaginal delivery $(n=44)$ and $30.8 \%$ of cesarean section $(\mathrm{n}=32)$. 44 have given birth vaginally $(42.3 \%)$ and 32 by caesarean section (30.8\%). It's young patient (28 years), nulliparous $(42.3 \%)$. Average time between instrumental extraction indication and the delivery of the baby was $58 \mathrm{~min}$ in the case of instrumental extraction and 1 hour 41 minutes in the case of spontaneous delivery in anticipation of the c-section. Motherhood had 3 instrumental extractors (2 vacuum extractors and 1 forceps) recycled after each use. The Apgar score was good in $85.7 \%$ in children born by instrumental extraction and bad in $54.5 \%$ in children born vaginally without instrumental extraction. We found 20 stillborn in intra partum occurred only in children born vaginally without instrumental extraction. Twelve (12) cases of bleeding of the issue by uterine atony (27.3\%) were recorded in patients pregnant without instrumental extraction. No maternal deaths were observed. Conclusion: The realization of instrumental extraction rate remains low at the maternity of the UH-C. In the event, the fetal prognosis was better.
\end{abstract}




\section{Keywords}

Instrumental Extraction, Forceps, Vacuum Extractor, Availability, Stillbirth

\section{Introduction}

In Côte d'Ivoire, stillbirth remains high, 49 per thousand [1] This stillbirth occurs especially during the expulsive phase of labor [1]. Rapid fetal extraction by vacuum extraction or by forceps permits to save fetal lives [2] [3] [4] [5] [6]. This practice which is part of the "Emergency Neonatal Obstetric Cares" is little assessed at the maternity of University Hospital of Cocody. We conducted this study, whose general objective was to do the overview of situation of instrumental extraction, by assessing the availability of that procedure when needed, and maternofetal prognosis.

\section{Methodology}

The study took place in the maternity of the UH-C. It's a retrospective and descriptive study of 6 months; January $1^{\text {st }}, 2015$, to June $30^{\text {th }}, 2015$. The studied population was all parturient in expulsive phase of labor and with an indication of fetal instrumental extraction and their newborns. The parturient who did not present an indication of instrumental extraction have not been included in the study. The studied parameters were demographics, gynecological and obstetric history, type of instrumental extraction and fetal and maternal prognosis. Neonatal prognosis has been assessed by the quotation of the Apgar score at birth to 1 minute and 5 minutes of live. A score above or equal 7 is considered good. Below 7 on the 5th minute of life, the score is bad. The data collection was made from the patient record and different records: birth, death and neonatal transfer. The statistical treatment was made from the software Epi info version 6.04 .

\section{Results}

\subsection{Clinical Data}

We recorded over the period of study 2288 births including 28 instrumental deliveries or $1.2 \%$ of births by instrumental extraction. We had only 3 instrumental extractors including 2 vacuum extractors and 1 forceps. A total of 104 indications of fetal extraction, there are 16 deliveries by vacuum extractor (15.4\%), 12 by forceps (11.5\%), 44 by spontaneous vaginal deliveries $(42.3 \%)$ and 32 by emergency c-section (30.8\%). There have been a total 28 instrumental deliveries is a rate of achievement of instrumental extraction of $26.9 \%$ and 76 cases of indication of instrumental extraction not executed (73.1\%). The directions were as follows: 72 cases of bad pushing efforts (69.2\%) and 32 cases of acute fetal distress $(30.8 \%)$. The 76 remaining patients, 44 have given birth vaginally $(42.3 \%)$ and 32 by caesarean section (30.8\%). The sociodemographic profile of our patients was as follows: patient older than 28 years on average and often nulliparous $(42.3 \%)$ (cf. Table 1). The average deportation time between the indication 
Table 1. Socio-demographic characteristics.

\begin{tabular}{cccc}
\hline Socio-demographic characteristics & N & Percentage \\
\hline & $15-19$ & 8 & 7.7 \\
Age & $20-24$ & 24 & 23.1 \\
(in years) & $25-29$ & 36 & 34.6 \\
& $30-34$ & 20 & 19.2 \\
& $>35$ & 12 & 15.4 \\
& Nulliparous & 44 & 42.3 \\
Parity & Primipara & 32 & 26.9 \\
& Paucipara & 24 & 23.1 \\
& Multipara & 8 & 7.7 \\
& & 104 & 100 \\
\hline
\end{tabular}

of fetal extraction and the birth was 58 minutes in the case of instrumental extraction, of $3 \mathrm{~h} 22 \mathrm{~min}$ in the case of caesarean section and 1 hour 41 minutes in the case of spontaneous vaginal.

\subsection{Fetal and Maternal Prognosis}

The Apgar score was good in $85.7 \%$ of neonate born by instrumental extraction (Table 2) and $62.5 \%$ of neonate by caesarean section. None of newborns by spontaneous vaginal without instrumental extraction had a good Apgar score. $54.5 \%$ of children born vaginally without instrumental extraction. We found 20 intra-partum death occurred only in children born by spontaneous vaginal delivery without instrumental extraction (Table 2). 12 cases of hemorrhage by uterine atony (11.5\%) were observed into the group of labouring women who had not chance to benefit to caesarean-section, however necessary for their management. No maternal deaths were noted.

\section{Discussion}

\subsection{Clinical Data}

Our practice of instrumental extraction represented $1.2 \%$ of vaginal deliveries. However, in the case of indication of instrumental extraction, our realization rate was $26.9 \%$. In the regional literature, at 2008 in Mali for example, Traore [2] reported a rate of instrumental extraction of $3.7 \%$, which is higher than ours. But, elsewhere in the sub region, the realization rate is low [3] [4] [5] [6]. In developed countries [7], instrumental extraction rate is much higher than ours. It was $10.4 \%$ into the perinatalogy network nominated Aurore in France [7]. Our low rate could be explained by an insufficient material. Our maternity had only 2 vacuum extractors and 1 re-usable forceps after sterilization. This sub equipment was explained by a lack of acquisition of new equipment. The lack of training of 
Table 2. Distribution of the newborns according to delivery mode and APGAR score at 5 minutes of live.

\begin{tabular}{ccccccc}
\hline & \multicolumn{5}{c}{ Delivery mode } \\
\cline { 2 - 7 } APGAR score & $\begin{array}{c}\text { Spontaneous vaginal } \\
\text { delivery }\end{array}$ & \multicolumn{2}{c}{ Cesarean-section } & \multicolumn{2}{c}{$\begin{array}{c}\text { Assisted vaginal } \\
\text { delivery }\end{array}$} \\
\cline { 2 - 7 } & $\mathbf{n}$ & $\%$ & $\mathrm{n}$ & $\%$ & $\mathrm{n}$ & $\%$ \\
\hline $\mathbf{0}$ & 20 & 45.5 & 0 & 0 & 0 & 0 \\
$\mathbf{1}-\mathbf{3}$ & 0 & 0 & 4 & 12.5 & 0 & 0 \\
$\mathbf{6}-\mathbf{7}-10$ & 24 & 54.5 & 8 & 25 & 8 & 14.3 \\
Total & 0 & 0 & 20 & 62.5 & 24 & 85.7 \\
\hline
\end{tabular}

$\mathrm{X}^{2}=131.4(\mathrm{~S}) \mathrm{ddl}=3$.

physicians in the use of an instrument of fetal extraction would be another reason. Indeed only senior doctors have been trained in this practice. Interns and doctors in specialization, providing the guards, were not able to use these instruments because of a lack of training. Generally, a small share of the national budget is assigned to the health care in our developing countries. Regarding the type of instrumental extraction, we found a clear predominance by vacuum extractor $(57.1 \%)$. Boni [8], in the same department in 2006, was a large predominance of the use of vacuum of $95 \%$ against $5 \%$ for the forceps. The use of vacuum extractor was easier than that forceps with easy learning as suggests several studies [7] [9] [10] [11]. The indications were dominated by the bad pushing efforts (69.2\%) and the acute fetal distress (30.8\%). The signs were similar in many African studies [2] [3] [6]. Maternal exhaustion and the abusive use of oxytocin in women fatigued by a long labor would most often a maternal tiredness at the moment of expulsive phase of labor justifying assistance to expulsion. In most of the studies as our, the young age of the patients (28 years) and the nulliparous [3] [4] [5] [6] were often observed. Indeed, inexperience, bad maternal pushing efforts, physical exhaustion in expulsive phase of labor, rigid perineum, constitute the main reasons of instrumental extraction.

\subsection{Fetal and Maternal Prognosis}

In our context of developing countries, the status of the newborn has been assessed by the Apgar score, which is an important criterion of assessment of neonatal prognosis [12]. We didn't realize arterial or venous $\mathrm{pH}$ in the umbilical cord blood. Thus, the Apgar score at 5 minutes of life was good (above 7) in $85.7 \%$ of neonate born by instrumental extraction and $62.5 \%$ of neonate born by caesarean section. Zero neonates born by spontaneous vaginal delivery got a good Apgar score. The majority of authors agree on the improvement of the Apgar score in case of fast instrumental extraction [2] [6] [8] [13]. In our study, Apgar score was bad in $54.5 \%$ of neonate born by spontaneous vaginal delivery. 
According to [14], the time of expulsion in the event of instrumental extraction was 30 min significantly lower than ours. This long delay in our study could be explained by a delay of acquisition of material, several attempts of instrumental extraction resulted in failures. These failures would be due to the inexperience of users (internal, doctors in the year of specialization). This long delay had an impact on fetal status at birth. In addition, a precarious fetal state represented by $30.8 \%$ (32 cases) of suffering fetal acute, was already present. We found 20 cases of intra partum death occurred only in the group of neonate born by spontaneous vaginal delivery. We did not record neonatal deaths attributable to instrumental extraction. In Senegal, an obstetric team [6] noticed a very low mortality rate, $0.6 \%$ live births compared to data literature. These facts testify to improving fetal prognosis in case of instrumental extraction. In our study, we did not observe fetal complications associated with fetal extraction. This could be due to our low sampling. Data literature about complications were in relation with bump sero-blood type, injuries of eye, paralysis of the brachial plexus, paralysis of the facial nerve, the depression fracture [8] [15] [16] [17] [18] [19]. Concerning maternal prognosis, we did not note injuries of the maternal genital route. Furthermore, we recorded 12 cases of hemorrhage by uterine atony into the group of labouring women who had not benefit to caesarean-section, however necessary for their management. This atony is explained by the labor dystocia or too long [6]. But, there were no maternal deaths.

\section{Conclusion}

The ratio of instrumental extraction remains low at the maternity of University Hospital of Cocody. We are facing with a sub equipment of fetal instrumental extraction and absence of medical staff training. Yet in the event of instrumental extraction, the fetal prognosis was better. No case of maternal death was noted. We advocate the expansion of this practice, which is part of the "Emergency Neonatal Obstetric Cares" and reduces neonatal mortality in our developing countries.

\section{Ethical Approval}

The study was approved by the Institutional Ethics Committee.

\section{References}

[1] Côte d'Ivoire. The Ministry of Health. (2012) Report on the Situation of Maternal Mortality in 2012. Abidjan.

[2] Traore, M., Traore, Y., Teguette, I., Dicko, F., Traore Mounkoro, N., Sissoko, A., et al. (2008) Clinical Aspects and Prognosis of Deliveries by Vacuum Extractor at CHU Gabriel Touré. Journal SAGO, 9, 11-15.

[3] Traoré, B., Thera, T.A., Kokaina, C., Mounkoro, N., Teguete, I. and Traore, Y. (2010) Instrumental Extractions at the Maternity of Regional Hospital Center of Ségou, Mali: Retrospective Study during 12 Months about 87 Cases. Medecine $d$ Afrique Noire, 57, 71-76. 
[4] Adaji, S.E., Shittu, S.T. and Sule, S.O. (2009) Operative Vaginal Deliveries in Zaria, Nigeria. Annals of African Medicine, 8, 95-99. https://doi.org/10.4103/1596-3519.56236

[5] Ouattara, S., Some, A.D., Toure, B., Bambara, M. and Dao, B. (2012) Materno-Fetal Outcome after Delivery by Vacuum Extractor at CHU of Bobo-Dioulasso, Burkina Faso. Clinics in Mother and Child Health, 9, 3 p.

[6] Cisse, C.T., Niang, M.M. and Diouf, A.B. (2015) Indications and Prognosis of Fetal Instrumental Extractions. Journal Africain de Chirurgie, 3, 186-191.

[7] Dupuis, O. (2008) Training and Learning of Extractions. Journal de Gynecologie, Obstetrique et Biologie de la Reproduction, 37, 288-296. https://doi.org/10.1016/S0368-2315(08)74766-5

[8] Boni, S., Abauleth, R., Gondo, D., Koffi, A., Effoh, D. and Kone, N. (2005) Indications of Instrumental Extractions and Prognosis Materno-Fetal at $\mathrm{CHU}$ of Cocody. Journal de la $S A G O, 6,1-5$.

[9] Schaal, J.P., Equy, V. and Hoffman, P. (2008) Comparison Vacuum Extractor versus Forceps. Journal de Gynecologie, Obstetrique et Biologie de la Reproduction, 37, S231-S235. https://doi.org/10.1016/S0368-2315(08)74761-6

[10] Velemir, L., Vendittelli, F., Bonnefoy, C., Accoceberry, M., Savary, D. and Gallot, D. (2009) Learning Curve of Vacuum by the Residential Student: Preliminary Study. Journal de Gynecologie, Obstetrique et Biologie de la Reproduction, 38, 421-429. https://doi.org/10.1016/j.jgyn.2009.04.004

[11] Riethmuller, D., Ramanah, R., Maillet, R. and Schaal, J.P. (2008) Vacuum Extractor: Description, Mechanic, Indications and Contraindications. Journal de Gynécologie Obstétrique et Biologie de la Reproduction, 37, 210-221.

[12] Casey, B.M., Mc Intire, D.D. and Leveno, K.J. (2001) The Continuing Value of the Apgar Score for the Assessment of Newborn Infants. The New England Journal of Medicine, 344, 467-471. https://doi.org/10.1056/NEJM200102153440701

[13] Riethmuller, D., Schaal, J.P. and Maillet, R. (2001) Vacuum Extractor: Modern Instrument. Gynécologie Obstétrique \& Fertilité, 29, 648-661.

[14] Okunwobi-Smith, Y., Cooke, I. and Mackenzir, I.Z. (2000) Decision to Delivery Intervals for Assisted Vaginal Vertex Delivery. British Journal of Obstetrics and Gynaecology, 107, 467-471. https://doi.org/10.1111/j.1471-0528.2000.tb13263.x

[15] Johnson, J.H., Figueroa, R., Garry, D., Elimian, A. and Maulik, D. (2004) Immediate Maternal and Neonatal Effects of Forceps and Vacuum Assisted Deliveries. Obstetrics \& Gynecology, 103, 513-518. https://doi.org/10.1097/01.AOG.0000114985.22844.6d

[16] Baume, S., Cheret, A., Creveuil, C., Vardon, D., Herlicoviez, M. and Dreyfus, M. (2004) Complications of Childbirth Assisted by Vacuum Extractor. Journal de Gynécologie Obstétrique et Biologie de la Reproduction, 33, 304-311.

[17] Caughey, A.B., Sandberg, P.L., Zlatnik, M.G., Thiet, M.P., Parer, J.T. and Laros, R.K. (2005) Forceps Compared with Vacuum Rates of Neonatal and Maternal Morbidity. Obstetrics \& Gynecology, 106, 908-912. https://doi.org/10.1097/01.AOG.0000182616.39503.b2

[18] Gardella, C., Taylor, M., Benedetti, T., Hitti, J. and Critchlow, C. (2004) The Effect of Sequential Use of Vacuum and Forceps for Assisted Vaginal Delivery on Neonatal and Maternal Outcomes. American Journal of Obstetrics \& Gynecology, 185, 896-902.

[19] Laurie, S., Glezerman, M. and Sadan, O. (2005) Maternal and Neonatal Effects of Forceps and Vacuum Operative Delivery. International Journal of Gynecology \& Obstetrics, 89, 293-294. 